\title{
Expression of steroidogenic enzymes in human placenta according to the gestational age
}

\author{
SO-HYE HONG ${ }^{1}$, SEUNG CHUL KIM ${ }^{2}$, MEE-NA PARK ${ }^{1}$, JEA SIC JEONG ${ }^{1}$, SEUNG YUN YANG ${ }^{1}$, YOUNG JOO LEE ${ }^{2}$, \\ OK-NAM BAE ${ }^{3}$, HOE-SAENG YANG ${ }^{4}$, SUNGBAEK SEO ${ }^{1}$, KYU-SUP LEE $^{2}$ and BEUM-SOO AN ${ }^{1}$ \\ ${ }^{1}$ Department of Biomaterials Science, College of Natural Resources and Life Science/Life and \\ Industry Convergence Research Institute, Pusan National University, Busan, Gyeongsangnam 50463; \\ ${ }^{2}$ Department of Obstetrics and Gynecology, Biomedical Research Institute, School of Medicine, \\ Pusan National University, Busan, Gyeongsangnam 49241; ${ }^{3}$ College of Pharmacy, Hanyang University, \\ Ansan, Gyeonggi 15588; ${ }^{4}$ Department of Obstetrics and Gynecology, \\ Medical College, Dongguk University, Seoul 04620, Republic of Korea
}

Received March 26, 2018; Accepted February 11, 2019

DOI: $10.3892 / \mathrm{mmr} .2019 .10048$

\begin{abstract}
Female sex steroid hormones, including estradiol (E2) and progesterone (P4), serve significant physiological roles in pregnancy. In particular, E2 and P4 influence placenta formation, maintain pregnancy and stimulate milk production. These hormones are produced by ovaries, adrenal glands and the placenta, of which the latter is a major endocrine organ during pregnancy. However, the mechanism of hormone production during pregnancy remains unclear. In the present study, the regulation of steroid hormones and steroidogenic enzymes was examined in human placenta according to gestational age. In human placental tissues, expression levels of steroidogenic enzymes were determined with reverse transcription-quantitative polymerase chain reaction and western blotting. The mRNA and protein expression of CYP17A1, HSD17B3 and CYP19A1, which are associated with the synthesis of dehydroepiandrosterone (DHEA) and E2, was elevated at different gestational ages in human placenta. In addition, to evaluate the correlation between serum and placental-produced hormones, steroid hormone levels, including pregnenolone (PG), DHEA, P4, testosterone (T) and
\end{abstract}

Correspondence to: Professor Beum-Soo An, Department of Biomaterials Science, College of Natural Resources and Life Science/Life and Industry Convergence Research Institute, Pusan National University, 50 Cheonghak-ri, Busan, Gyeongsangnam 50463, Republic of Korea

E-mail: anbs@pusan.ac.kr

Dr Kyu-Sup Lee, Department of Obstetrics and Gynecology, Biomedical Research Institute, School of Medicine, Pusan National University, 179 Gudeok-ro, Seo-gu, Busan, Gyeongsangnam 49241, Republic of Korea

E-mail: kuslee@pusan.ac.kr

Key words: steroidogenesis, steroid hormones, placenta, pregnancy
E2, were examined in serum and placenta. Serum and placenta expression of DHEA and E2 increased with gestational age, whereas $\mathrm{T}$ and $\mathrm{P} 4$ were differently regulated in placenta and serum. To confirm the mechanism of steroidogenesis in vitro, placental BeWo cells were treated with E2 and P4, which are the most important hormones during pregnancy. The mRNA and protein expression of steroidogenic enzymes was significantly altered by E2 in vitro. These results demonstrated that concentration of steroid hormones was differently regulated by steroidogenic enzymes in the placenta depending on the type of the hormones, which may be critical to maintain pregnancy.

\section{Introduction}

The placenta is an organ that connects the developing fetus to the uterine wall for nutrient uptake, excretion, antibody transport and gas exchange via the maternal blood supply. The placenta begins to develop upon implantation of the blastocyst into the maternal endometrium (1). The outer layer of the blastocyst then develops into the trophoblast, which forms the placenta (1). This layer is further divided into two layers, including the underlying cytotrophoblast layer and overlying syncytiotrophoblast layer. Cytotrophoblatic cells serve an important role in the implantation of a newly fertilized egg in the uterus (2). The syncytiotrophoblast is the epithelial covering of the highly vascular embryonic placental villi, which invades the uterine wall to establish nutrient circulation between the embryo and mother (2).

Maternal endocrine adaptations to pregnancy involve the hypothalamus, pituitary, parathyroid, thyroid, adrenal glands and ovaries, and are linked to fetal-placental-maternal unit interactions. Maternal physiology during pregnancy is significantly affected by placental hormones such as estrogen, progesterone (P4), human chorionic gonadotropin (hCG), prolactin, parathyroid hormone, adrenal hormones and human placental lactogen (3). Female sex steroid hormones such as estradiol (E2) and P4 also have critical function during pregnancy. E2 and P4 have many functions associated with fetal 
development (4). In the case of estrogen, there are three major naturally occurring forms in women, including estrone (E1), E2 and estriol (E3) (4). Among these, E2 is the most potent and prevalent type of endogenous estrogen, although other metabolites of E2 also have estrogenic hormone activity and circulate at high levels at certain phases in the menstrual cycle and during pregnancy (5). Increasing levels of E2 during the follicular phase promote endometrial proliferation, which is further regulated by stimulating the secretion of prolactin, which also promotes breast growth and milk production (6). P4 prevents uterine contractions by promoting smooth muscle relaxation in the myometrium. During pregnancy, P4 causes developmental changes in the endometrium that are necessary for formation of the maternal portion of the placenta $(3,7)$.

Placental synthesis of E2 via conversion of steroid precursors requires the enzymes $3 \beta$-hydroxysteroid dehydrogenase type 1 (HSD3B1), aromatase (CYP19A1), and 17 $\beta$-hydroxysteroid dehydrogenase type 3 (HSD17B3) (8). In addition, key enzymes involved in the production of progesterone include side-chain cleavage enzyme (CYP11A1) and $17 \alpha$ hydroxylase (CYP17A1). Cholesterol is converted into PG by CYP11A1, which can be converted into P4 depending on HSD3B1. HSD17B3 is for androgen synthesis, producing testosterone from the precursor hormone androstenedione. CYP17A1 is a key enzyme in the steroidogenic pathway that produces $\mathrm{P} 4$, mineralocorticoids, glucocorticoids, androgen and E2 $(9,10)$.

Previous studies have determined the steroidogenic capacity and mechanism of the placenta during pregnancy in rats, mice, cats, ewes and other species $(11,12)$. However, depending on the animal species there are several placenta types, including discoid, zonary, cotyledonary and diffuse placentas. The mature human placenta is a discoid organ with a diameter of $20-25 \mathrm{~cm}$ and thickness of $3 \mathrm{~cm}$, that weighs 400-600 g (2). Since human placenta has a discoid shape, which has a different structure and physiological features from other species, physiological and functional studies on the placenta should be separately conducted in humans (13). In the present study, the expression levels of steroidogenic enzymes in human placenta was examined, according to the gestational age. In addition, the levels of steroid hormones in the serum and placenta were analyzed.

\section{Materials and methods}

Tissue and blood sample collection and grouping. The present study was approved by the Institutional Review Board of the Pusan National University Hospital Clinical Trials Center (approval no. H-1302-005-015). Placental tissue samples were received from Pusan National University Hospital and collected after informed consent was obtained. Placenta

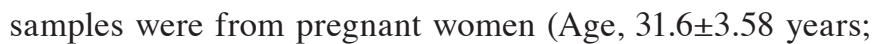
collection dates between July 2012 and February 2014) who met the following inclusion criteria: i) Singleton pregnancy; ii) normal pregnancy at time of sample collection; and iii) healthy women with no preexisting clinical conditions, including diabetes, hypertension, or autoimmune disease. The normal placenta samples were divided into early preterm (22-29 week gestation; $n=10)$, late preterm (30-36 week gestation; $n=18)$, and term (37-40 week gestation; $n=20)$ groups following labor onset. The placental tissues were previously confirmed by testing expression of tissue specific marker, corticotropin-releasing hormone (14).

Human placental-derived BeWo cell culture. BeWo human choriocarcinoma-derived cells were cultured in Dulbecco's modified Eagle's medium (DMEM; Gibco; Thermo Fisher Scientific, Inc., Waltham, MA, USA), supplemented with $10 \%$ fetal bovine serum (FBS; Gibco; Thermo Fisher Scientific, Inc.) and $1 \%$ streptomycin/penicillin at $37^{\circ} \mathrm{C}$ in a humidified atmosphere of $5 \% \mathrm{CO}_{2}$, and allowed to attach during $24 \mathrm{~h}$ of incubation, following which the medium was removed and replaced with phenol-red free experimental medium (Sigma-Aldrich; Merck KGaA, Darmstadt, Germany) treated with charcoal-dextran FBS (Gibco; Thermo Fisher Scientific, Inc.) for $24 \mathrm{~h}$ before treatment. steroid hormones were dissolved in ethanol, diluted with experimental medium, and added to wells for $24 \mathrm{~h}$ at room temperature. Cells were exposed a physiological concentrations of E2 (100 nM), P4 $(10 \mu \mathrm{M})$ or ethanol as a vehicle control $(15,16)$.

Reverse transcription-quantitative polymerase chain reaction $(R T-q P C R)$. Total RNA from cells and tissues were extracted using TRIzol ${ }^{\circledR}$ reagent (Invitrogen; Thermo Fisher Scientific, Inc., Waltham, MA, USA) according to the manufacturer's protocol. Total RNA concentration was measured using a spectrophotometer. DNA (cDNA) was prepared from total RNA $(1 \mu \mathrm{g})$ by $\mathrm{RT}$ at $37^{\circ} \mathrm{C}$ for $60 \mathrm{~min}$ using M-MLV reverse transcriptase (Invitrogen; Thermo Fisher Scientific, Inc.) and random primers (9-mers; Takara Bio, Inc., Otsu, Japan). qPCR was performed using cDNA template $(2 \mu \mathrm{l})$ and SYBR Green (6 $\mu$ l; Toyobo Life Science, Osaka, Japan) with specific primers. The primer sequences for CYP11A1, HSD3B1, CYP17A1, HSD17B3, CYP19A1 and $\beta$-actin are shown in Table I. qPCR was carried out for 40 cycles using the following parameters: denaturation at $95^{\circ} \mathrm{C}$ for $15 \mathrm{sec}$, annealing at $55^{\circ} \mathrm{C}$ for $15 \mathrm{sec}$, and extension at $72^{\circ} \mathrm{C}$ for $45 \mathrm{sec}$. Fluorescence intensity was measured at the end of each extension phase. The threshold value for the fluorescence intensity of all samples was set manually. The reaction cycle at which PCR products exceeded this fluorescence intensity threshold during the exponential phase of PCR amplification was considered to be the cycle of threshold (CT). Expression of the target gene was quantified relative to that of $\beta$-actin, a housekeeping gene, based on comparison of CTs at constant fluorescence intensity (17).

Western blotting analysis. Protein samples were extracted from placental tissue with PRO-PREP ${ }^{\mathrm{TM}}$ solution (iNtRON Biotechnology, Seoul, Korea) and from BeWo cells with protein extraction reagent (Thermo Fisher Scientific, Inc.). A total of $25 \mu \mathrm{g}$ of protein per lane was separated by $10-12 \%$ SDS-PAGE and transferred onto nitrocellulose membranes. The membranes were blocked for $2 \mathrm{~h}$ at room temperature with $5 \%$ skimmed milk or 5\% donkey serum (Sigma-Aldrich; Merck KGaA) in PBS with 0.05\% Tween-20 (PBS-T). Next, membranes were incubated with antibodies specific for CYP11A1 (1:1,000; cat. no. 14217, Cell Signaling Technology, Inc., Dallas, TX, USA), HSD3B1 (1:2,000; ab55268, Abcam, Cambridge, MA, USA), CYP17A1 (1:500; sc-66850, Santa 
Table I. Primer sequences for quantitative polymerase chain reaction analysis.

\begin{tabular}{|c|c|c|c|}
\hline Gene name & Primer & Sequence $\left(5^{\prime}-3^{\prime}\right)$ & Fragment size (bp) \\
\hline \multirow[t]{2}{*}{$\beta$-actin } & Forward & GGACTTCGAGCAAGAGATGG & 234 \\
\hline & Reverse & AGCACTGTGTTGGCGTACAG & \\
\hline \multirow[t]{2}{*}{ CYP11A1 } & Forward & GCAACGTGGAGTCGGTTTAT & 229 \\
\hline & Reverse & AGGGGCAAAAAGTTCTTGGT & \\
\hline \multirow[t]{2}{*}{ HSD3B1 } & Forward & AGAGGCCTGTGTCCAAGCTA & 152 \\
\hline & Reverse & TTTTGCTGTGTGGGTATGGA & \\
\hline \multirow[t]{2}{*}{ CYP17A1 } & Forward & CTGATGCAAGCCAAGATGAA & 222 \\
\hline & Reverse & GCTGAAACCCACATTCTGGT & \\
\hline \multirow[t]{2}{*}{ HSD17B3 } & Forward & ATCCAGAGCCTCATCCATTG & 164 \\
\hline & Reverse & AACGCCTTGGAAGCTGAGTA & \\
\hline \multirow[t]{2}{*}{ CYP19A1 } & Forward & CCAGTGAAAAAGGGGACAAA & 175 \\
\hline & Reverse & CCATGGCGATGTACTTTCCT & \\
\hline
\end{tabular}

CYP11A1, side-chain cleavage enzyme; HSD3B1, 3ß-hydroxysteroid dehydrogenase type 1; CYP17A1, 17 $\alpha$ hydroxylase; HSD17B3, 17ß-hydroxysteroid dehydrogenase type 3; CYP19A1, aromatase.
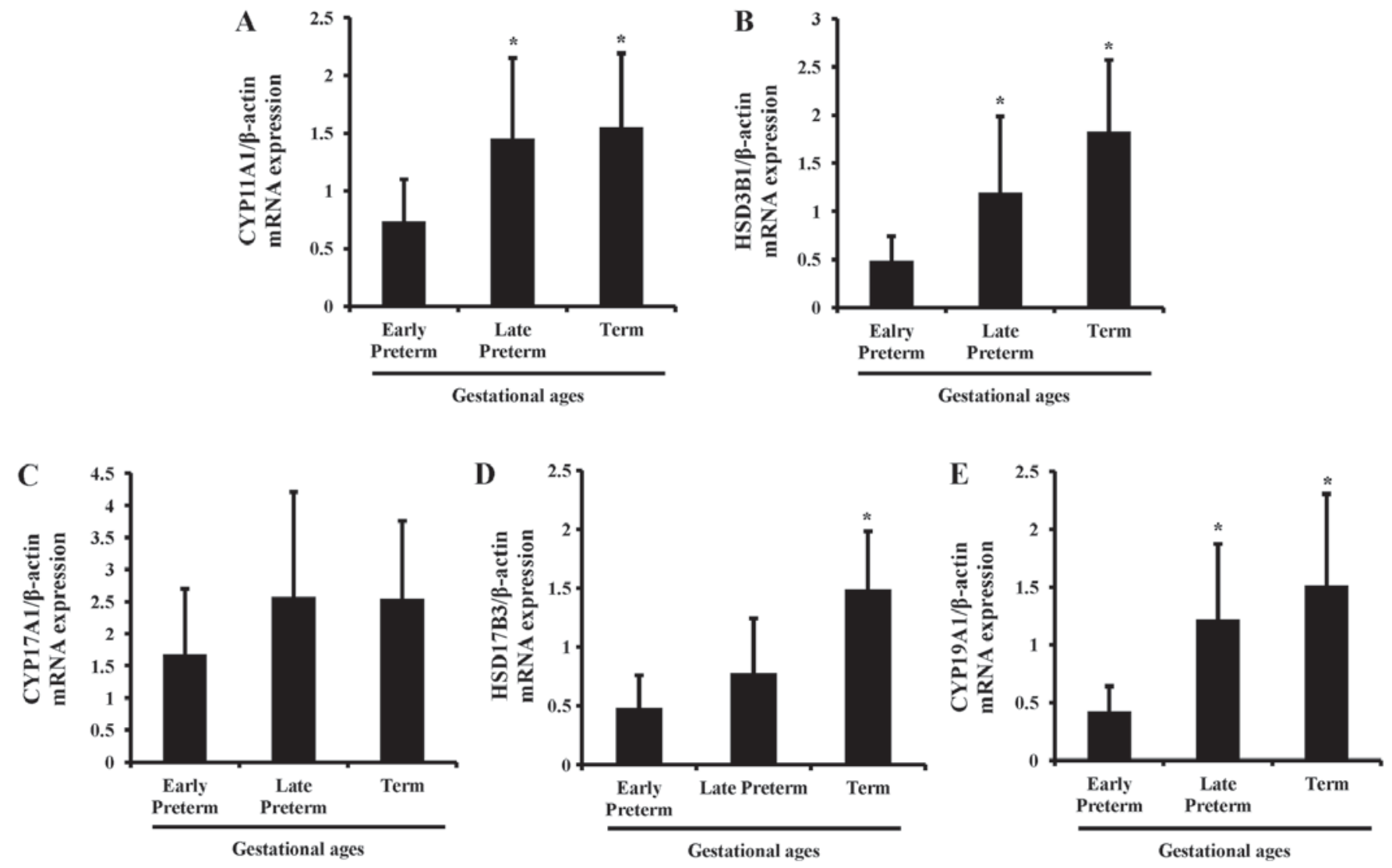

Figure 1. mRNA expression of steroidogenic enzymes during gestation in human placenta. Total mRNA was harvested from human placenta following the onset of labor. Gene expression of (A) CYP11A1, (B) HSD3B1, (C) CYP17A1, (D) HSD17B3 and (E) CYP19A1 was analyzed by quantitative polymerase chain reaction and normalized to $\beta$-actin. Data are expressed as the mean \pm standard deviation. ${ }^{*} \mathrm{P}<0.05$ vs. early preterm group. CYP11A1, side-chain cleavage enzyme; HSD3B1, 3 $\beta$-hydroxysteroid dehydrogenase type 1; CYP17A1, 17 $\alpha$ hydroxylase; HSD17B3, 17 $\beta$-hydroxysteroid dehydrogenase type 3; CYP19A1, aromatase.

Cruz Biotechnology, Inc., CA, USA), HSD17B3 (1:2,000; ab126228, Abcam), CYP19A1 (1:500; sc-14245, Santa Cruz Biotechnology, Inc.) and $\beta$-actin (1:3,000; cat. no. 4970, Cell
Signaling Technology, Inc.) overnight at $4^{\circ} \mathrm{C}$. Following this, membranes were incubated with horseradish peroxidase-conjugated anti-rabbit (1:2,000; sc-2030, Santa Cruz 
A
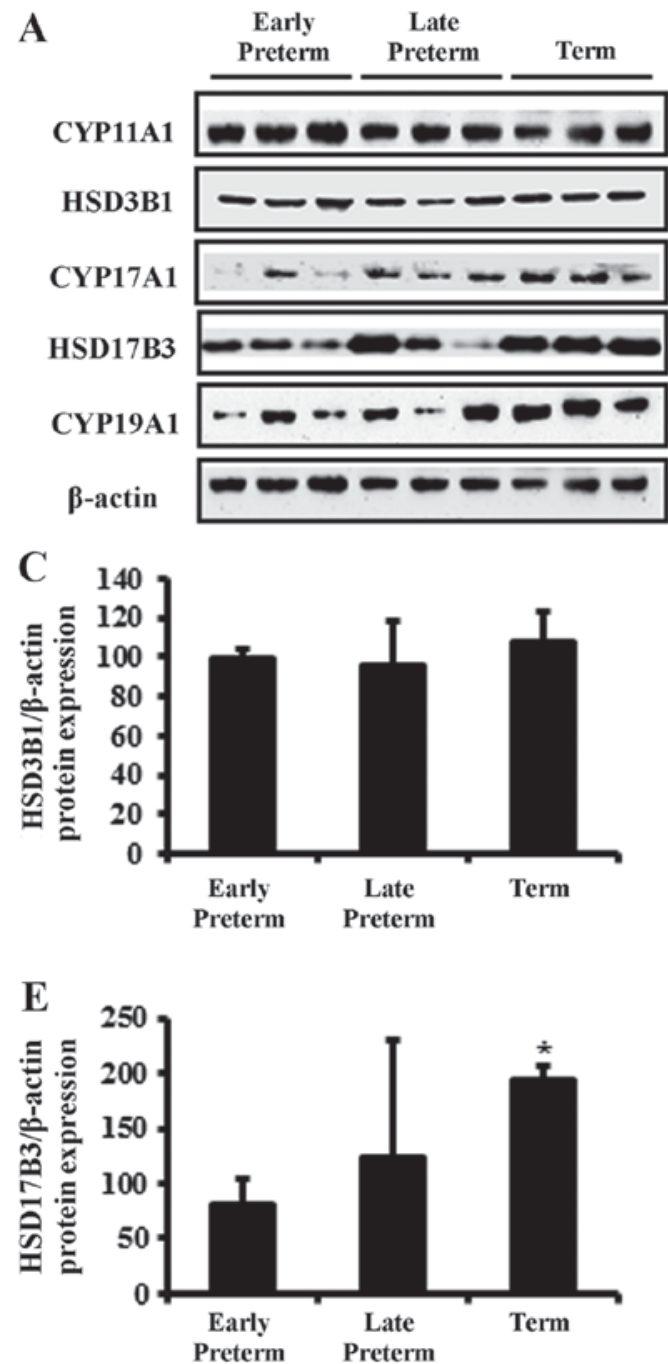

B

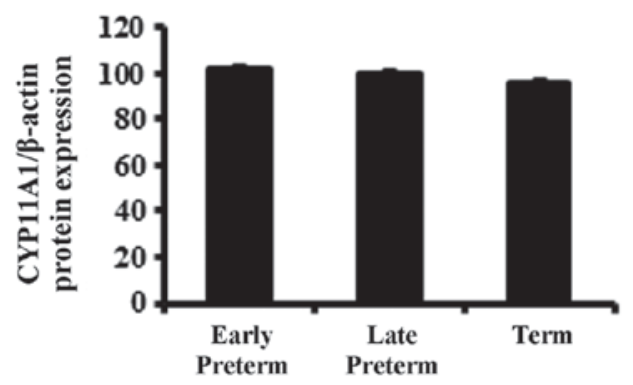

D
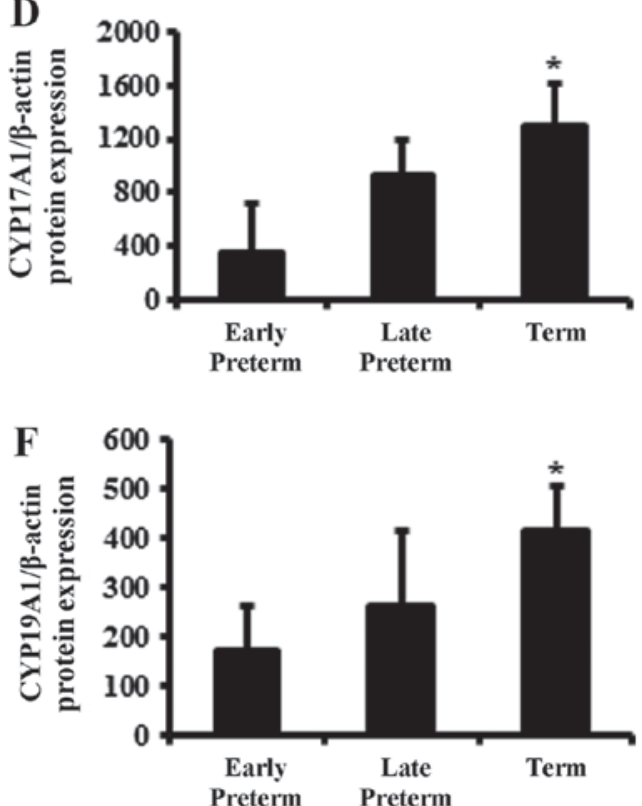

Figure 2. Protein expression of steroidogenic enzymes during gestation in human placenta. (A) Total protein was harvested from human placenta following the onset of labor for western blot analysis. The protein expression of (B) CYP11A1, (C) HSD3B1, (D) CYP17A1, (E) HSD17B3 and (F) CYP19A1 was quantified and normalized to $\beta$-actin. Data are expressed as the mean \pm standard deviation. ${ }^{*} \mathrm{P}<0.05$ vs. early preterm group. CYP11A1, side-chain cleavage enzyme; HSD3B1, 3 $\beta$-hydroxysteroid dehydrogenase type 1; CYP17A1, 17 $\alpha$ hydroxylase; HSD17B3, 17 $\beta$-hydroxysteroid dehydrogenase type 3; CYP19A1, aromatase.

Biotechnology, Inc.), anti-mouse (1:2,000; cat. no. 7076, Cell Signaling Technology, Inc.) and anti-goat (1:2,000; sc-2020, Santa Cruz Biotechnology, Inc.) secondary antibodies in blocking solution at room temperature for $1 \mathrm{~h}$. Luminol reagent (Bio-Rad Laboratories, Inc., Hercules, CA, USA) was used to visualize antibody binding. Each blot was scanned using Gel Doc 1000, version 1.5 (Bio Rad Laboratories, Inc.), and band intensities were normalized to $\beta$-actin.

Histological analysis. Placental tissues were fixed with $10 \%$ formalin overnight, embedded in paraffin wax, routinely processed and sectioned into $4 \mu \mathrm{m}$ thick slices. The sections were deparaffinized with xylene, rehydrated with ethanol at graded decreasing concentrations of $100-70 \%$, and finally washed with distilled water. The slides with placental sections were stained with hematoxylin and eosin (Sigma-Aldrich; Merck KGaA) and washed with distilled water. For immunohistochemistry (IHC), endogenous peroxidase activity was quenched using a $10 \mathrm{~min}$ incubation step with $3 \%$ hydrogen peroxide $\left(\mathrm{H}_{2} \mathrm{O}_{2}\right)$ in methanol. Non-specific binding was blocked by incubation with $10 \%$ bovine serum albumin (BSA; Sigma-Aldrich; Merck KGaA) and the slides were incubated with primary antibody solution (CYP11A1 (1:200; ab175408, Abcam), HSD3B1 (1:2,000; ab55268, Abcam), CYP17A1 (1:500; sc-66850, Santa Cruz Biotechnology, Inc.) and CYP19A1 (1:500; sc-14245, Santa Cruz Biotechnology, Inc.) overnight at $4^{\circ} \mathrm{C}$. The slides were then washed three times for 2 min each in PBS while slowly warming to room temperature, followed by incubation with secondary antibody (horseradish peroxidase-conjugated anti-rabbit (1:100; sc-2030, Santa Cruz Biotechnology, Inc.), anti-mouse (1:1,000; cat. no. 7076, Cell Signaling Technology, Inc.) for $10 \mathrm{~min}$ at room temperature. Primary antibody detection was performed with a Polink-2 Plus HRP DAB kit (GBI Labs, Bothell, WA, USA). Images of tissue were captured at $\mathrm{x} 40$ using a model BX50F-3 optical microscope (Olympus, Tokyo, Japan) and examined visually.

ELISA. Following E2 treatments, BeWo cell-cultured media were centrifuged at $1,300 \mathrm{x}$ g for $15 \mathrm{~min}$ at $4^{\circ} \mathrm{C}$ and stored at $-80^{\circ} \mathrm{C}$. $\mathrm{P} 4$ accumulation in media was measured using 
Table II. Concentration of steroid hormones in serum and placenta.

\begin{tabular}{|c|c|c|c|c|c|c|}
\hline \multirow[b]{2}{*}{ Steroid hormone } & \multicolumn{3}{|c|}{ Serum } & \multicolumn{3}{|c|}{ Placenta } \\
\hline & Early preterm & Late preterm & Term & Early preterm & Late preterm & Term \\
\hline PG (ng/ml) & $7.0 \pm 0.0$ & $7.0 \pm 0.0$ & $7.0 \pm 0.1$ & $7.0 \pm 0.0$ & $7.0 \pm 0.0$ & $7.1 \pm 0.0$ \\
\hline DHEA (ng/ml) & $10.3 \pm 1.1$ & $12.1 \pm 0.7^{\mathrm{a}}$ & $12.6 \pm 0.6^{\mathrm{a}}$ & $8.4 \pm 0.7$ & $9.9 \pm 0.6^{\mathrm{a}}$ & $11.0 \pm 0.8^{\mathrm{a}}$ \\
\hline P4 (ng/ml) & $4.4 \pm 0.1$ & $5.3 \pm 0.2$ & $5.7 \pm 0.2^{\mathrm{a}}$ & $2.8 \pm 0.1$ & $2.8 \pm 0.1$ & $2.8 \pm 0.3$ \\
\hline $\mathrm{T}(\mathrm{ng} / \mathrm{ml})$ & $2.6 \pm 0.3$ & $3.0 \pm 0.3$ & $3.1 \pm 0.2^{\mathrm{a}}$ & $3.3 \pm 0.2$ & $3.1 \pm 0.2$ & $2.9 \pm 0.1^{\mathrm{a}}$ \\
\hline E2 (ng/ml) & - & - & - & $11.8 \pm 2.2$ & $14.6 \pm 2.4^{\mathrm{a}}$ & $18.5 \pm 2.1^{\mathrm{a}}$ \\
\hline
\end{tabular}

Data are presented as the mean \pm standard deviation. ${ }^{a} \mathrm{P}<0.05$ vs. early preterm group. $\mathrm{PG}$, pregnenolone; DHEA, dehydroepiandrosterone; $\mathrm{P} 4$, progesterone; T, testosterone; E2, estradiol.

a competitive enzyme immunoassay kit (582601; Cayman Chemical Company, Ann Arbor, MI, USA) following the manufacturer's protocol.

Blood was collected in plastic tubes under aseptic conditions with ethylene diamine tetra-acetic acid as an anti-coagulant, followed by centrifugation in order to separate plasma. Serum and human placenta proteins were collected from each volunteer and stored at $-80^{\circ} \mathrm{C}$, following which the sample was slowly thawed at room temperature. Pregnenolone (PG), dihydroepiandrosterone (DHEA), E2, P4, and testosterone $(\mathrm{T})$ concentrations were measured using an ELISA kit following the manufacturer's protocol. ELISA kits for PG and DHEA were from Alpco Diagnostics (11-PREHU-E01; Salem, NH, USA) and Enzo Life Science (ADI-900-093; Ann Arbor, USA). E2, P4, and T ELISA kits were purchased from Cayman Chemical (E2, 582251; P4, 582601; T, 582701).

Statistical analysis. Results are presented as the mean \pm standard deviation). Data were analyzed using a post hoc Tukey's test following one-way analysis of variance (Sigma Plot version 10.0; Systat Software, Inc., San Jose, CA, USA). $\mathrm{P}<0.05$ was considered to indicate a statistically significant difference.

\section{Results}

mRNA levels of steroidogenic enzymes in the placenta during gestation. To evaluate the mRNA expression of steroidogenic enzymes in human placenta according to gestational age, qPCR was carried out in tissues of early preterm, late preterm and term placentas. As gestational age increased, the mRNA expression of steroidogenic enzymes was elevated in human placenta and maximized in the term period. Among the genes, CYP11A1, HSD3B1, HSD17B3 and CYP19A1 were significantly increased, compared with the early preterm group; whereas the changes in CYP17A1 expression were not significant (Fig. 1).

Proteinlevels of steroidogenic enzymes in placentaduring gestation. Protein expression levels of steroidogenesis-associated enzymes in human placenta according to gestational age were also investigated by western blotting (Fig. 2A). The protein expression of CYP11A1 and HSD3B1 was not significantly altered (Fig. 2B and C). However, similar to the mRNA expression results, the protein levels of CYP17A1, HSD17B3 and CYP19A1 were elevated in term placenta, compared with the early preterm group (Fig. 2D-F).

Serum levels of steroid hormones according to gestational age. As steroid hormone biosynthesis-related enzymes in placenta was differentially regulated according to gestational age, the concentration of steroid hormones in human serum and placenta was determined with ELISAs. Concentrations of DHEA and P4 were higher in serum than placenta, whereas the concentration of E2 was higher in placenta than serum during all periods of gestation (Table II). PG levels were stable and similar between the serum and placenta. For gestational stage, serum levels of DHEA, P4, T and E2 were significantly elevated at term compared with the early preterm group. Concentrations of steroid hormones including DHEA and E2 in placental tissue showed similar patterns to those in serum, by elevating at term stage. Notably, the level of $\mathrm{T}$ in placenta was reduced in term placenta, which was opposite from serum concentration. The level of P4 was also different from serum, which was not changed according to gestational age.

Histological analysis of steroidogenic enzymes in placental tissue. To determine steroidogenic enzyme localization, immunostaining was performed in late preterm placenta. Placental tissue was stained with hematoxylin $\&$ eosin to confirm the morphology of placental tissue (Fig. 3A). Tissue sections were immunostained with specific antibodies of proteins and counter-stained with $\mathrm{H} \& \mathrm{E}$ to show the spatial localizations of CYP11A1 (Fig. 3B), HSD3B1 (Fig. 3C), CYP17A1 (Fig. 3D), and CYP19A1 (Fig. 3E). In the image, the cytotrophoblast section was surrounded with a layer of syncytiotrophoblasts, which is a general morphological feature of placenta. Steroidogenic enzymes, including HSD3B1, CYP17A1 and CYP19A1, were localized to both cyto- and syncytiotrophoblast cells, and signals were more dominant in syncytiotrophoblast cells. However, expression of CYP11A1 was negligible in placenta.

Regulation of steroidogenic enzymes by E2 and P4. For the next experiment, the expression levels of steroidogenic 
A

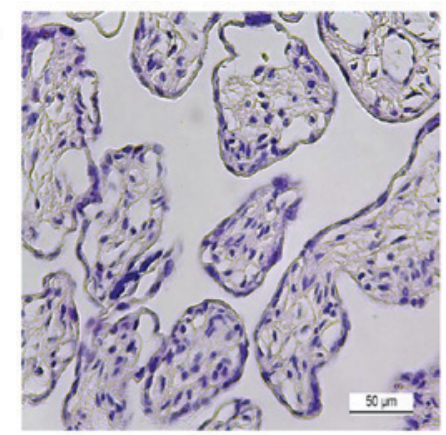

B

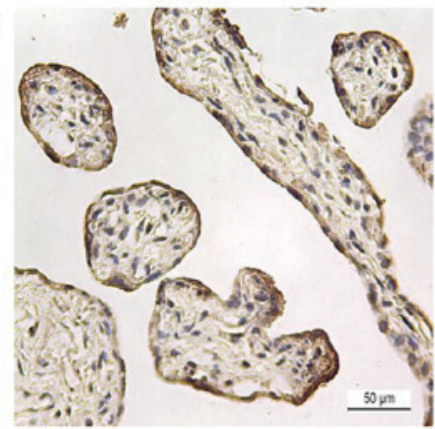

C

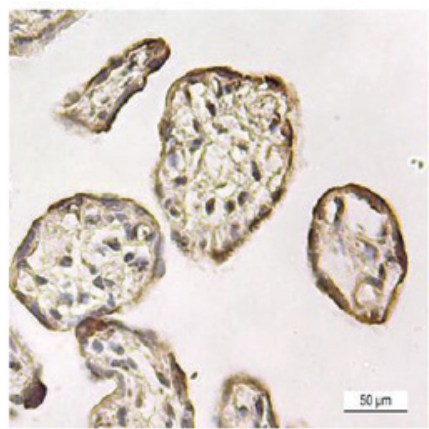

D

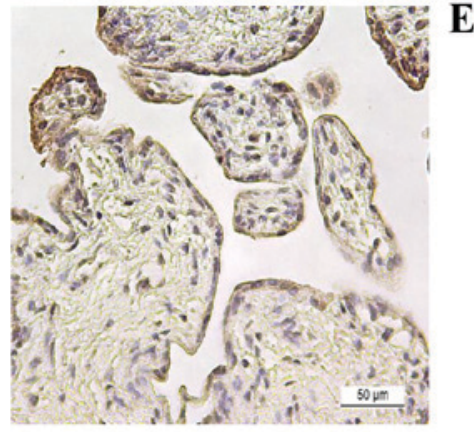

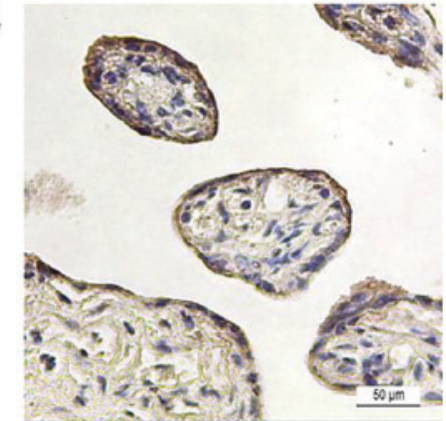

Figure 3. Immunostaining of steroidogenic enzymes in late preterm stage of pregnancy in human placental tissue. (A) Placental tissue was stained with hematoxylin \& eosin to confirm the morphology of placental tissue. To examine localization of each protein, tissues were stained with specific antibodies for (B) CYP11A1, (C) HSD3B1, (D) CYP17A1 and (E) CYP19A1. Magnification, x40. CYP11A1, side-chain cleavage enzyme; HSD3B1, 3ß-hydroxysteroid dehydrogenase type 1; CYP17A1, 17 $\alpha$ hydroxylase; CYP19A1, aromatase.
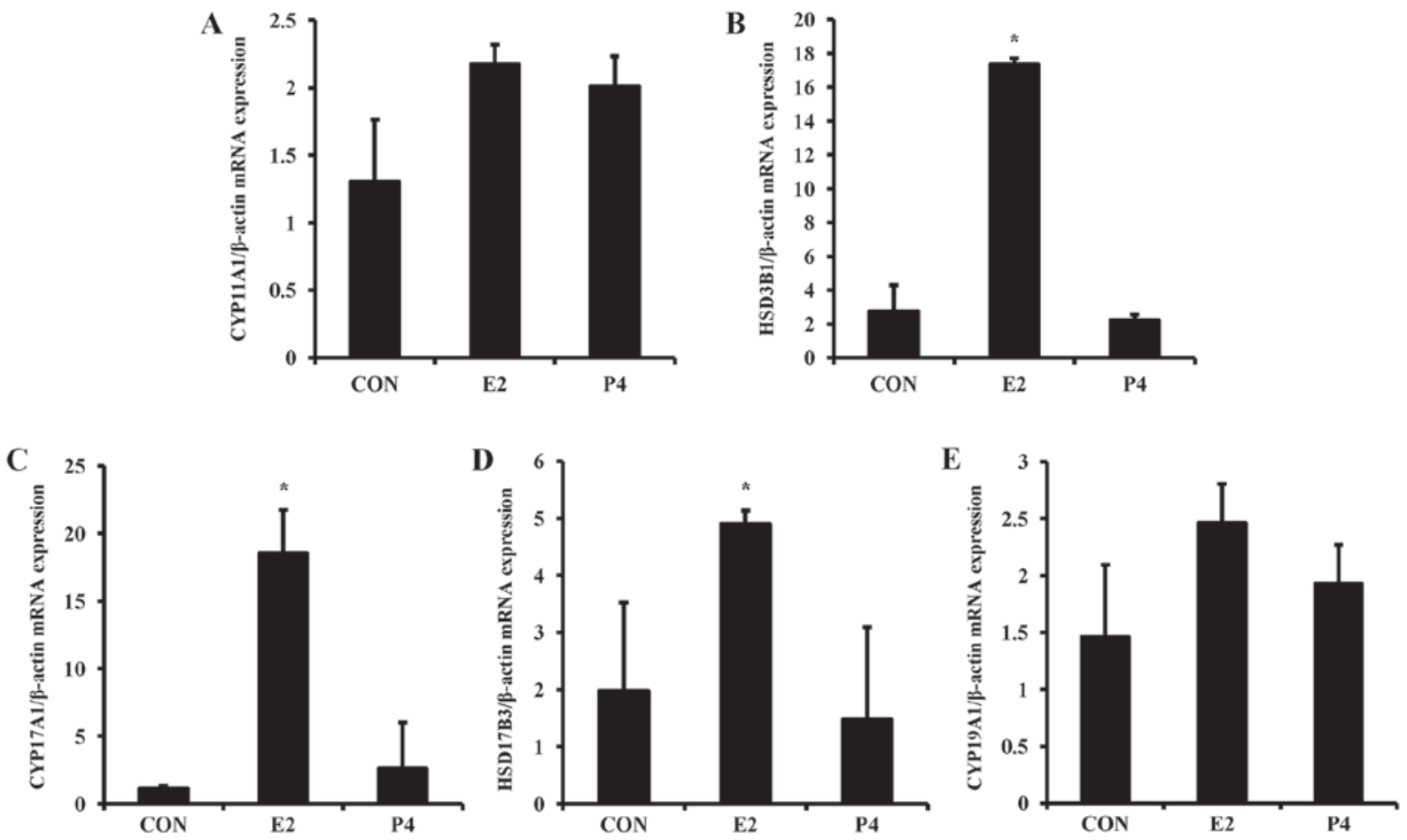

Figure 4. mRNA expression of steroidogenic enzymes in placental-derived BeWo cells. Total mRNA was harvested from BeWo cells, and gene expression of (A) CYP11A1, (B) HSD3B1, (C) CYP17A1, (D) HSD17B3 and (E) CYP19A1 was analyzed quantitative polymerase chain reaction and normalized to

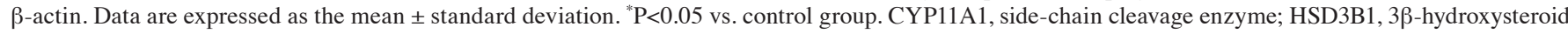
dehydrogenase type 1; CYP17A1, 17 $\alpha$ hydroxylase; HSD17B3, 17ß-hydroxysteroid dehydrogenase type 3; CYP19A1, aromatase.

enzymes in placental-derived BeWo cells was examined. To evaluate the mechanism of steroidogenic enzyme regulation, BeWo cells were treated with E2 and P4, which are critical hormones during pregnancy (2), for $24 \mathrm{~h}$. The mRNA expression of HSD3B1, CYP17A1, and HSD17B3 was significantly elevated by E2 in BeWo cells (Fig. 4), 

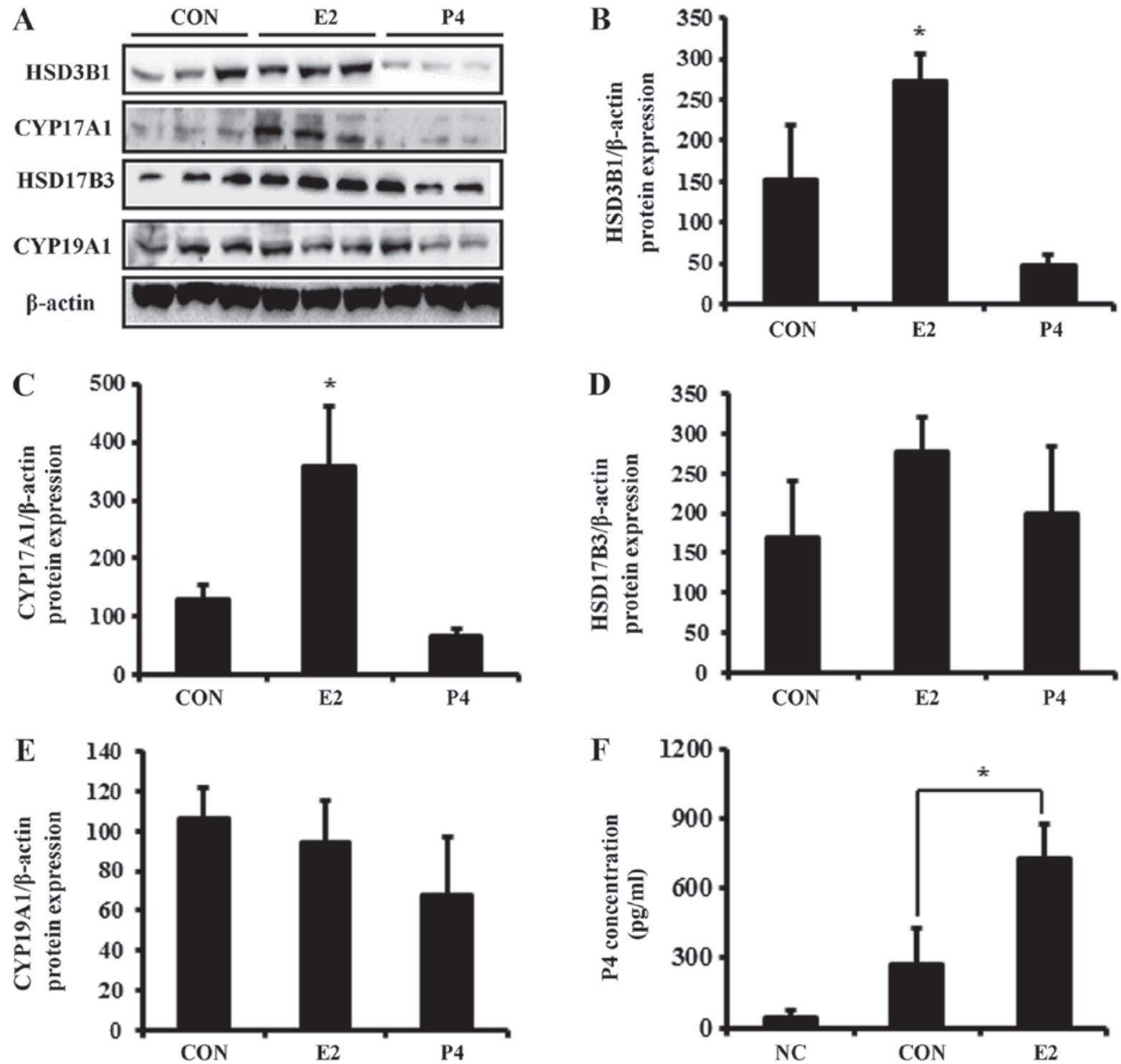

Figure 5. Protein expression of steroidogenic enzymes and P4 secretion in response to E2 and P4 treatment in placental-derived BeWo cells. (A) Total protein was harvested from BeWo cells for western blot analysis. Expression of (B) HSD3B1, (C) CYP17A1, (D) HSD17B3 and (E) CYP19A1 was quantified and normalized to $\beta$-actin. (F) Following treatment of BeWo cells with E2, medium was harvested and P4 concentration was analyzed with ELISAs. Data are expressed as the mean \pm standard deviation. ${ }^{*} \mathrm{P}<0.05$ vs. control group. NC, culture media without cells; CON, culture media with BeWo cells treated with vehicle; HSD3B1, 3 $\beta$-hydroxysteroid dehydrogenase type 1; CYP17A1, 17 $\alpha$ hydroxylase; HSD17B3, 17 $\beta$-hydroxysteroid dehydrogenase type 3; CYP19A1, aromatase; E2, estradiol; P4, progesterone.

whereas P4 did not alter mRNA expression of these steroidogenic enzymes. Similar to the mRNA results, E2 increased protein expression of steroidogenesis-associated enzymes (Fig. 5A). Translation levels of HSD3B1, CYP17A1, and HSD17B3 were elevated 2- to 3-fold in response to E2 treatment, whereas levels of CYP19A1 were not significantly altered (Fig. 5B-E).

Analysis of $\mathrm{P} 4$ secretion after $\mathrm{E} 2$ treatment. As the expression of steroidogenic enzymes was elevated by E2, the modulation of $\mathrm{P} 4$ secretion was further investigate following $\mathrm{E} 2$ treatment in BeWo cell-cultured media. P4 expression in conditioned cultured media (control group) collected from BeWo cells was $0.27 \mathrm{ng} / \mathrm{ml}$ (Fig. 5F). E2 increased production of P4 by 3 -fold compared with the control, which was consistent with the expression results of P4-metabolizing enzymes.

\section{Discussion}

Steroid hormones are mainly produced by steroidogenesis, which is the biological process by which steroids are generated from cholesterol or transformed into other steroids. Humans and mammals predominantly synthesize active steroid hormones from cholesterol mainly in the reproductive glands and placenta (9). During normal pregnancy, women experience numerous adjustments in their endocrine system (18). Levels of E2 and P4 dramatically increase throughout pregnancy, suppressing the hypothalamic axis and subsequently the menstrual cycle (19). Due to their various functions, E2 and P4 are associated with various physiological disorders during pregnancy such as pre-eclampsia and premature birth (20).

In the current study, the expression of steroidogenic enzymes were examined in human placenta according 
to gestational age. The mRNA and protein expression of steroidogenic enzymes was upregulated with gestational age in placenta tissue. To analyze the association between serum and placental steroid hormones, the concentrations of steroid hormones in human serum and placenta were examined. In the results, serum DHEA, P4 and T was elevated in the term stage of pregnancy, whereas PG levels were not significantly altered according to gestational age. In our previous study, serum E2 levels were shown to be enhanced in the late stage of gestation (20). In addition to serum, steroid hormones from placental tissue, including PG, DHEA, P4, T and E2 were examined. Similar to the serum results, DHEA and E2 levels were elevated in the term stage of pregnancy, whereas PG and P4 levels were not altered. Unlike the serum results, placental $\mathrm{T}$ levels were reduced in the term stage of pregnancy. It is possible that serum $\mathrm{T}$ levels are elevated by the fetal steroidogenic system, which stimulates negative feedback inhibition of the hormone in maternal placenta (21). These results indicated that expression of steroidogenic enzymes in placental tissue was enhanced with gestational age, resulting in elevated serum and placenta levels of E2 and DHEA in the term stage of gestation. However, some steroid hormones such as $\mathrm{P} 4$ and $\mathrm{T}$ were differently regulated in the placenta and serum. In addition, the basal levels of the hormones including DHEA, P4, and T in serum at each duration were occasionally higher than those of placenta. These results suggested that not all steroid hormones originated from placenta, indicating the involvement of other organs, including maternal ovary and adrenal glands, as well as the fetal endocrine system. To further examine the endocrine regulatory mechanism in the placenta, placental-derived BeWo cells were treated with E2 and P4. E2 treatment upregulated the expression of steroidogenesis-associated enzymes that were not significantly regulated by P4. Since steroidogenic enzymes were significantly modulated by E2 only, $\mathrm{P} 4$ secretion in BeWo cell-cultured media following E2 treatment was additionally examined. As expected, BeWo cells showed higher secretion of $\mathrm{P} 4$ compared to the control group, indicating that the steroidogenic process was enhanced by E2 via a positive feedback mechanism.

The results of the present study show that E2 is more important than P4 in human placenta in terms of its effects on steroidogenesis during pregnancy, which is different from previous studies on other species $(11,12)$. In cats, placental P4 concentrations appear to be independent on gestational age (11). In bovines, the maternal placenta contributes significantly to steroidogenesis in early pregnancy, particularly for the synthesis of P4 (12). These controversial results may be due to the different physiological features of placenta depending on the species. In addition, different steroidal circumstances may contribute to different interactions and communication between mother, placenta and fetus in humans $(7,19)$.

In summary, the levels of steroid hormones in human placenta and serum were investigated according to gestational age. As the gestational age increased, expression levels of steroidogenic enzymes were stimulated in the placenta, which may constitute the elevation of serum DHEA and E2. The in vitro study suggested that this regulation of steroidogenic enzyme expression was attributed to increased E2 levels via a positive feedback mechanism in the late stage of gestation. The critical roles of the regulated steroid hormones during gestation should be investigated in future studies in order to understand physiological ramifications of pregnancy.

\section{Acknowledgements}

Not applicable.

\section{Funding}

This study was supported by a grant from the Korea Health Technology R\&D Project through the Korea Health Industry Development Institute (KHIDI), funded by the Ministry of Health \& Welfare, Republic of Korea (grant no. HI16C0313).

\section{Availability of data and materials}

The biospecimens and data used for this study were provided by the Biobank of Pusan National University Hospital, a member of the Korea Biobank Network. The datasets used and/or analyzed during the current study are available from the corresponding author on reasonable request.

\section{Authors' contributions}

SHH, MNP, JSJ, ONB and SS performed the experiments. SCK, YJL and HSY collected human samples. SHH, KSL and BSA wrote the article. KSL and BSA designed the project. SCK, SYY, YJL, ONB, HSY, SS and KSL contributed to the discussion. SYY also provided experimental materials.

\section{Ethics approval and consent to participate}

The present study was approved by the Institutional Review Board of the Pusan National University Hospital Clinical Trials Center (approval no. H-1302-005-015). Placental tissue samples were received from Pusan National University Hospital and collected after informed consent was obtained.

\section{Patient consent for publication}

Not applicable.

\section{Competing interests}

The authors declare that they have no competing interests.

\section{References}

1. Pijnenborg R, Bland JM, Robertson WB, Dixon G and Brosens I: The pattern of interstitial trophoblastic invasion of the myometrium in early human pregnancy. Placenta 2: 303-316, 1981.

2. Gude NM, Roberts CY, Kalionis B and King RG: Growth and function of the normal human placenta. Thromb Res 114: 397-407, 2004.

3. Gailly-Fabre E, Kerlan V and Chirstin-Maitre S: Pregnancy-associated hormones and fetal-maternal relations. Ann Endocrinol (Paris) 76: S39-S50, 2015.

4. Albrecht ED and Pepe GJ: Estrogen regulation of placental angiogenesis and fetal ovarian development during primate pregnancy. Int J Dev Biol 54: 397-408, 2010.

5. Gruber CJ, Tschugguel W, Schneeberger C and Huber JC: Production and actions of estrogens. N Engl J Med 346: 340-352, 2002.

6. Zhu BT and Conney AH: Functional role of estrogen metabolism in target cells: Review and perspectives. Carcinogenesis 19: 1-27, 1998. 
7. Murphy VE, Smith R, Giles WB and Clifton VL: Endocrine regulation of human fetal growth: The role of the mother, placenta, and fetus. Endocr Rev 27: 141-169, 2006.

8. Pepe GJ and Albrecht ED: Actions of placental and fetal adrenal steroid hormones in primate pregnancy. Endocr Rev 16: 608-648, 1995.

9. Payen AH and Hales DB: Overview of steroidogenic enzymes in the pathyway from cholesterol to active steroid hormones. Endocr Rev 25: 947-970, 2004.

10. Miller WL and Auchus RJ: The molecular biology, biochemistry, and physiology of human steroidogenesis and its disorders. Endocr Rev 32: 81-151, 2011.

11. Siemieniuch MJ, Jursza E, Szostek AZ, Skarzynski DJ, Boos A and Kowalewski MP: Steroidogenic capacity of the placenta as a supplemental source of progesterone during pregnancy in domestic cats. Reprod Biol Endocrinol 10: 89, 2012.

12. Verduzco A, Fecteau G, Lefebvre R, Smith LC and Murphy BD: Expression of steroidogenic proteins in bovine placenta during the first half of gestation. Reprod Fertil Dev 24: 392-404, 2012.

13. Furukawa S, Kuroda Y and Sugiyama A: A comparison of the histological structure of the placenta in experimental animals. J Toxicol Pathol 27: 11-18, 2014.

14. Kim SC, Park MN, Lee YJ, Joo JK and An BS: Interaction of steroid receptor coactivators and estrogen receptors in the human placenta. J Mol Endocrinol 56: 239-247, 2016.
15. Gambino YP, Perez Perez A, Duenas JL, Calvo JC, Sanchez-Margalet V and Varone CL: Regulation of leptin expression by 17 beta-estradiol in human placental cells involves membrane associated estrogen receptor alpha. Biochim Biophys Acta 1823: 900-910, 2012

16. Frazier K, Wallace K and LaMarca B: Progesterone inhibits trophoblast TNF alpha production. The FASEB J 24, 2010.

17. Livak KJ and Schmittgen TD: Analysis of relative gene expression data using real-time quantitative PCR and the $2^{-\Delta \Delta \mathrm{CT}}$ method. Methods 25: 402-408, 2001.

18. Costantine MM: Physiologic and pharmacokinetic changes in pregnancy. Front Pharmacol 5: 65, 2014.

19. Kurnar P and Magon N: Hormones in pregnancy. Niger Med J 53: 179-183, 2012.

20. Robboy SJ and Hoda RS: Pathology of the human placenta. Int J Gynecol Pathol 19: 401, 2000.

21. Rodeck CH, Gill D, Rosenberg DA and Collins WP: Testosterone levels in midtrimester maternal and fetal plasma and amniotic fluid. Prenat Diagn 5: 175-181, 1985. 